\title{
THREE-DIMENSIONAL PRINTING BY FUSED DEPOSITION MODELING (3DP-FDM) IN PHARMACEUTICS
}

\author{
KINGA ILYÉS, ANDREA-GABRIELA CRIȘAN, ALINA PORFIRE*, IOAN TOMUȚĂ \\ Department of Pharmaceutical Technology and Biopharmacy, Faculty of Pharmacy, University of Medicine and Pharmacy \\ "Iuliu Hațieganu”, Cluj-Napoca, Romania
}

*corresponding author: aporfire@umfcluj.ro

Manuscript received: February 2020

\begin{abstract}
The three-dimensional printing (3DP) of the plastic materials is considered as a modern alternative to pharmaceutical manufacturing. Fused deposition modelling (FDM) is a versatile 3DP technique that enables the simple production of complex pharmaceutical dosage forms with personalization potential. This application can be exploited for therapeutic purposes; however, it is important to understand the material and technological considerations, the advantages and disadvantages of the technology in order to produce pharmaceutical products of the required quality.
\end{abstract}

\section{Rezumat}

Imprimarea tridimensională a materialelor plastice este considerată o alternativă modernă pentru fabricația medicamentelor. Modelarea prin depunerea filamentului topit este o tehnică versatilă de imprimare tridimensională care permite fabricarea simplă a unor forme farmaceutice complexe cu potențial de personalizare ridicat. Această caracteristică poate fi exploatată în diverse scopuri terapeutice, însă este importantă înțelegerea considerentelor materiale și tehnologice, a avantajelor şi dezavantajelor, pentru a putea fabrica produse farmaceutice de calitate.

Keywords: 3D printing, fused deposition modelling, melt extrusion, tailored dosage forms

\section{Introduction}

The approval of Spritam ${ }^{\circledR}$ (Levetiracetam) from Aprecia in 2015 [24] by the United States Food and Drug Agency (FDA) pointed out that the pharmaceutical domain was ready to accept three dimensional printing (3DP) as an alternative manufacturing process. This launched a wave of studies evaluating how each 3DP technology can be exploited for therapeutic purposes. The notion of 3DP includes a wide variety of technologies dependent on the main mechanism that enables layerby-layer structure formation $[17,18]$. The extrusionbased methodologies (fused deposition modelling FDM and pressure assisted microsyringe - PAM) are the most researched in the medical area, with more than $80 \%$ of the articles published in the last five years relying on these technologies [9]. Both present advantages of simplicity, flexibility and accessibility, for PAM the major drawback from the pharmaceutical perspective being the need to use organic solvents, which may cause stability issues with the active compound along the manufacturing and drying steps [31] and upon ingestion should be limited as per the permitted daily exposure [22].

The present review focuses specifically on the pharmaceutical potential of 3DP-FDM, discussing its technological and material requirements, pharmaceutical potential, as to finally predict its prospects with regards to its applicability with advantages and drawbacks.

\section{Technological overview}

For the printing process, industrial and desktop 3DP-FDM printers can be employed [99]. Although productivity and accuracy are higher for the industrial settings, desktop printers are catching up quickly and represent a fast, user friendly and cost-effective solution for research and development. Up to this point, for pharmaceutical purposes, mostly desktop Cartesian printers were assessed for suitability.

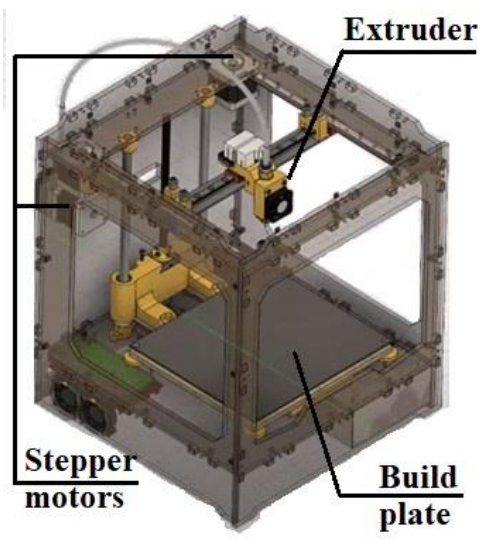

Figure 1.

The general construction of the Cartesian printer with the 3 main elements (image adapted from [7]) 
By construction, the Cartesian printers are rather simple, with three main elements - extruder, build plate and stepper motors - that enable 3D form production (Figure 1). As a general overview, the extruder deposits material in the conventional two dimensions on a build plate moving in vertical plan, enabling the production of a 3D object layer-by-layer.

Along the printing process the material is fed, melted and extruded. The active pharmaceutical ingredient (API) carrier in this case is a filament, drug loading being assured with or without the use of organic solvents. Earlier studies relied on the immersion of commercially available filaments (usually polyvinyl alcohol) within an API loaded solution, however this technique required additional processing steps and assured a lower loading success rate, from $0.063 \%$ to $5 \%[34,36,88,93]$, therefore nowadays 3DP-FDM is preponderantly used in conjunction with hot melt extrusion (HME) [58]. Up to $60 \%$ drug loadings could be incorporated within thermoplastic polyurethane based filaments without compromising its 3DP-FDM processability [100]. HME relies on the same technological substrate as 3DP-FDM, the material being loaded in powder or pellet form, conveyed, melted and finally extruded though a narrow extrusion die. The difference relies in the existence of an additional mixing phase, which is crucial for homogeneity and is more efficient in the case of twin screw extruders compared to single screw extruders $[82,97]$.

The integral workflow of the combined HME and 3DPFDM methodology is illustrated with Figure 2.

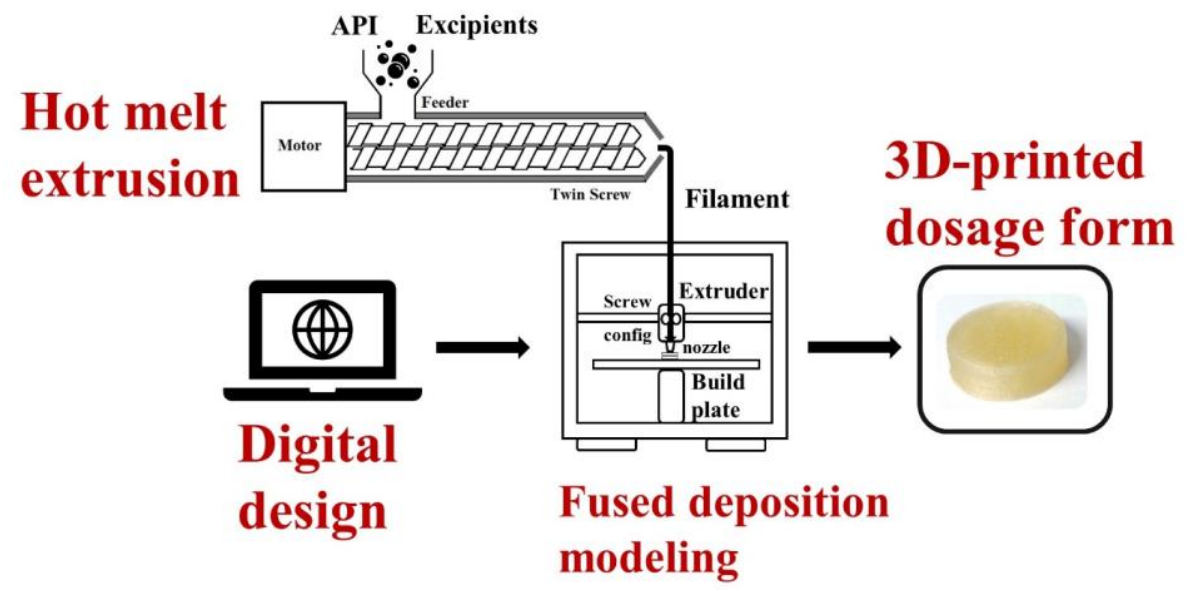

Figure 2.

The workflow in the combined fused deposition modelling and hot melt extrusion methodology

Still, not every material that is hot melt extrudable can be fused deposition modelled, troubleshooting being related to filament feeding and/or melt deposition [49]. Within the extruder of printer, the filament is fed by a screw configuration to a heating unit, where, once melted, it is pushed by the piston action of the incoming solid material through a nozzle of specific diameter. As such, the material should respond with optimal viscosity to the applied thermal and shear stress, but also have adequate mechanical features (brittleness against rigidity) to be able to mobilize the melt even through a reduced extrusion diameter, without breaking or slipping along the process $[2,30,72]$. Printability is enabled by finding the appropriate combination between material properties and technological settings. The process parameters of 3DP-FDM that can be modulated are the following: print temperature, print speed, build plate temperature. All three parameters influence rheological and mechanical response of the material substrate and influence quality by modulating the degree of thermal shock that the API receives during printing. It is important to note, that in the case of the HME + 3DP-FDM methodology, there is dual thermal impact, which means that both production phases should be controlled and correlated. Although, generally, 3DP-FDM requires higher processing temperatures, the risk of degradation is higher in HME due to the composition's longer residence time within the heating unit. Previous studies suggest that, in printing, working below the critical TGA limit of the API and above 30 $\mathrm{mm} / \mathrm{s}$ print speeds, reduces the impact of 3DP-FDM to minimum [49]. However, not all compositions can be printed at higher velocities at a given temperature, the melting being insufficient in relation to the feeding force, the filament bending, breaking with the subsequent interruption of the process. So preferably, the extrusion and deposition temperatures should be reduced as much as possible. Currently the lowest temperature of printing was $90^{\circ} \mathrm{C}$ for an optimally associated Kollidon ${ }^{\circledR}$ VA 64 and Kollidon ${ }^{\circledR} 12$ PF based polymeric blend, conditions in which the degradation of ramipril was prevented [63]. Print speed was also determined to significantly influence print reproducibility (weight and dimensional accuracy) [4].

Compared to the conventional, compressed dosage forms, in 3DP design modulation is performed digitally. 
Like all 3DP techniques, production starts by creating a computer-aided design (CAD) model of the desired product or a digital scan, which, by means of a Standard Tessellation Language (STL) format, is reassigned to a slicing program, where the design and process settings are translated into machine readable instructions (Gcode). As mentioned earlier, the construction is done layer-by-layer, which enables the easy customization of the design by a relatively easy process. The advantages of design modulation will be discussed in the section Pharmaceutical potential of the current paper.

\section{Material requirements}

The selection of excipients is fundamental in the design of pharmaceutical delivery systems, in addition for 3DPFDM it is particularly critical in granting technological feasibility and assuring successful printing outcomes. As seen in section Technological overview, the performance of the printing phase is highly dependent on rheomechanical features of the filament, which in turn is dependent on the materials used.

For material selection it is essential to understand the properties that enable quality and printability. The most important requirement for 3DP-FDM, especially when combined with HME, is to ensure materials that, at the given processing conditions, would not degrade [13]. For printability, thermo-plasticity is the main enabler, which defines the ability to change viscoelastic properties when subjected to thermal and shear energy. The materials should be able to appropriately flow when pressure-extruded and subsequently solidify upon deposition and cooling [73]. Viscosity is the most important rheological parameter to describe the flow. The lowering of viscosity is beneficial in mobilizing the melt, but to a certain degree viscosity is necessary to obtain a stable geometry post-extrusion. For 3DPFDM it is insufficient to talk only about critical rheological features, as mechanical and thermal characteristics are equally important and influence directly the melt flow through the nozzle. The phase transitions within melt are governed by temperature, while mechanics together with the motor torque influence the degree of shear that is applied onto the melt. Thermic behaviour is defined by the degradation temperature (Td), glass transition temperature (Tg), melting temperature (Tm), while for mechanics, characteristics like stiffness, flexibility and brittleness should be taken into account when evaluating filaments for the 3DP-FDM purpose.

Commercially available filaments of butadiene styrene (ABS), polylactic acid (PLA), polyvinyl alcohol (PVA), high-impact polystyrene (HIPS), high-density polyethylene (HDPE), nylon, polycarbonate (PC) possess optimal material features for 3DP-FDM and have been widely used for rapid prototyping by 3DP-FDM [94]. The initial attempts to transfer the 3DP-FDM technology to the pharmaceutical field relied on the exploitation of ready-to-use PVA filaments [34, 36, 47, 88, 91]. However, this sort does not qualify for the highly regulated area of pharmaceutical manufacturing, therefore alternative, pharmaceutical grade polymeric blends were tested for suitability.

Pharmaceutical materials are more problematic, as such understanding material properties and formulation rationale play a pivotal role in adapting pharmaceutical compositions to 3DP-FDM. Polymers are the most important constituents of thermoplastic filaments. Their selection is based on the compatibility with the API and the desired functional outcome, however being, in most cases, the most abundant constituents their molecular properties also determine printability. High molecular weight, high degree of branching, high linear chain length increase melt viscosity by increasing the ability to withstand deformation [96], as such may cause difficulties upon extrusion. However, low molecular weight is associated with poor mechanical features. The same correlation was determined by Isreb et al. when investigating the influence of polyethylene oxide (PEO) molecular weight on filament formation. Lower molecular weight sorts of PEO (100 - $200 \mathrm{~K})$ were determined to be too brittle, breaking under the pressure of the screw configuration, while the high molecular weight types $(900 \mathrm{~K})$ provided inadequate material flow due to increased viscosity. Optimal properties were identified for PEO with molecular weights between 300 and $600 \mathrm{~K}$ [50]. Molecular properties can also impact thermic behaviour. The lower size and reduced complexity can accelerate phase transition upon heating. Beyond molecular features the molecular arrangement or crystal structure is also to be considered. The phase transition for amorphous polymers is referred to as the $\mathrm{Tg}$, while crystalline polymers have Tm. Tg marks the relaxation transition from the glass to rubber-like state characterized by enhanced polymer chain mobility, while Tm points out the transition point from an ordered to a disordered structure. Semi-crystalline polymers exhibit both $\mathrm{Tg}$ and $\mathrm{Tm}$, as they have both amorphous and crystalline regions [55, 96]. Pharmaceutical polymers are typically amorphous (polymethacrylates - Eudragit ${ }^{\circledR}$ polymers) or semi-crystalline (polyvinyl alcohol, polylactic acid, polycaprolactone). The API itself can be also amorphous or crystalline, with the crystalline being the preferential form based on the lower internal energy [11]. During thermal treatment, the amorphization of the crystalline API is possible [29, 49]. The thermal properties are determinant in material screening and indicative in establishing processing conditions. Having low $\mathrm{Td}$ or $\mathrm{Tg}$ too close to $\mathrm{Td}$ has a discriminatory effect as degradation is at risk. The very versatile hydroxypropyl methylcellulose (HPMC) posed problems from this point of view, exhibiting high melt viscosities even at temperature close to the degradation point. As a resolution, HPMC is used with plasticizers to correct $\mathrm{Tg}$ or is interchanged with an alternative, HME destined sort, Affinisol ${ }^{\mathrm{TM}}$, with lower Tg and 
FARMACIA, 2020, Vol. 68, 4

improved melt flow [43, 46, 79]. For processing, typically the Tm, or, if not present, the $\mathrm{Tg}$ values of the polymer, should be followed, but the miscible/ soluble small-molecule APIs can alter/lower these values by decreasing the friction amid the long and entangled polymer sequences $[1,89,90]$. The API loading has however some limitations. By increasing the load, the solubility can be exceeded, the crystal fraction creating the vulnerability point where the filament can break [98].

3DP-FDM functional blends can already be formed by the simple mixture of the API with the polymer $[56,79,105]$. However, by adding additional adjuvant materials (plasticizers, fillers etc.) processability can be improved. Having multicomponent polymeric fractions can be taken into account based on the same consideration. Most commonly, plasticizers are included in preparations with the purpose of decreasing processing temperature, if thermal stability is at risk.
Other benefits of plasticizer addition include improving flowability of the molten mass and augmenting flexibility of the filament. They act by increasing spacing between polymer chains, ultimately reducing $\mathrm{Tg}$, melt viscosity and stiffness [61]. As such, they improve printability only up to a certain point and the rate in which they are included is to be carefully considered. Triacetin [78], sorbitol [76, 77], polyethylene glycols $[3,26,70,101]$, Tween ${ }^{\circledR} 80$ [3], triethyl citrate [20], etc. are representatives for this class of excipients and have been widely used in 3DP-FDM applications. Insoluble fillers such as magnesium stearate [38], talc [85], tri-calcium phosphate [85], microcrystalline cellulose [107], etc. can also be added to the mixtures. Their function is to assure consistent flow and reproducibility [85].

Table I gives an overview of the variety of materials and compositions that were used for 3DP-FDM.

Pharmaceutical polymeric blends with documented 3DP-FDM applicability

\begin{tabular}{|c|c|c|c|}
\hline Filament composition used (\%) & Dosage form & Drug Release Characteristics & Reference \\
\hline PVA (Parteck ${ }^{\circledR}$ MXP) : Sorbitol : Baclofen (80:10:10) & Minicaplet & Immediate release & [76] \\
\hline $\begin{array}{r}\text { PVA }\left(\text { Parteck }^{\circledR} \text { MXP) : Lisinopril dehydrate : Sorbitol : Titanium }\right. \\
\text { Dioxide }(56: 20: 23: 1)+ \\
\text { PVA : Amlodipine besylate : Sorbitol }(63: 10: 27)+ \\
\text { PVA : Indapamide : Sorbitol : Titanium Dioxide }(66.5: 5: 27.5: 1)+ \\
\text { PVA : Rosuvastatin calcium : Sorbitol : Titanium Dioxide } \\
(56: 20: 23: 1)\end{array}$ & $\begin{array}{l}\text { Multi-layered } \\
\text { polypill }\end{array}$ & Immediate release & [77] \\
\hline $\begin{array}{c}\left.\text { PVA (Mowiol }{ }^{\circledR} 4-88\right) \text { : Mannitol : Sodium chloride : PVP K } \\
\text { 30: Diltiazem }(55: 13: 7: 5: 20)+ \\
\text { Cellulose acetate : TEC }(75: 25)\end{array}$ & $\begin{array}{l}\text { Osmotic core } \\
\text { and semi- } \\
\text { permeable } \\
\text { shell caplet }\end{array}$ & $\begin{array}{l}\text { Sustained and/or delayed } \\
\text { release as per design }\end{array}$ & [29] \\
\hline 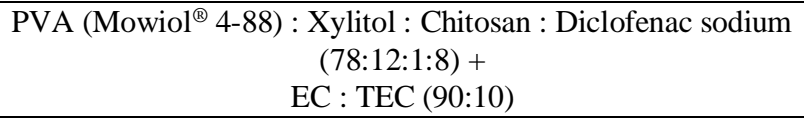 & Buccal film & Immediate release & [20] \\
\hline $\begin{array}{c}\text { PLA : PCL : PEG 4000: Tween 80: Progesterone } \\
(66: 17: 10: 2: 5)\end{array}$ & Vaginal ring & Sustained release & [26] \\
\hline $\begin{array}{c}\text { PCL : Zinc oxide (90:10) / (25:75) } \\
\text { PCL : Silver nitrate (90:10) } \\
\text { PCL : Copper sulphate }(90: 10) /(25: 75) \\
\end{array}$ & $\begin{array}{l}\text { Wound } \\
\text { dressing }\end{array}$ & Sustained release & [71] \\
\hline $\begin{array}{c}\text { PCL : Estrogen }(99: 1) \\
\text { PCL : Progesterone (99:1) }\end{array}$ & $\begin{array}{l}\text { Vaginal } \\
\text { Implant (IUD, } \\
\text { mesh, pessary) }\end{array}$ & Sustained release & [95] \\
\hline PVP : TEC : Talc : Theophylline : Dipyridamole (50:12.5:27.5:5:5) & Caplet & Immediate release & [75] \\
\hline $\begin{array}{l}\text { PVP : TEC : Talc }: \text { Theophylline }(50: 12.5: 27.5: 10) / \\
\text { PVP : TEC : Tribasic phosphate }: \text { Theophylline }(50: 12.5: 27.5: 10) / \\
\text { PVP : TEC : Talc : Budesonide }(50: 12.5: 35.2: 2.3) / \\
\text { PVP : TEC }: \text { Talc }: \text { Diclofenac Na }(45.5: 17.5: 17: 20) / \\
\text { + Eudragit L100-55 : TEC }: \text { Talc }(50: 16.67: 33.33)\end{array}$ & $\begin{array}{l}\text { Shell core } \mathrm{pH}- \\
\text { responsive } \\
\text { caplets }\end{array}$ & Delayed release & [74] \\
\hline $\begin{array}{c}\text { Kollidon }^{\circledR} \text { VA64 : Kollidon }{ }^{\circledR} \text { 12PF : Mannitol : Magnesium } \\
\text { carbonate : PEG 1500 : Ramipril (65:0:10:2:20:3) / } \\
\text { (39:26:10:2:20:3) / (32.5:32.5:10:2:20:3) }\end{array}$ & Printlets & Immediate release & [63] \\
\hline Kollicoat $^{\circledR}$ IR : Haloperidol (90:10) & Tablets & Immediate release & [89] \\
\hline $\begin{array}{c}\left.\text { HPMCAS (Aquot }{ }^{\circledR}\right) \text { LG : Methylparaben: magnesium stearate : } \\
\text { Paracetamol / } \\
\text { HPMCAS MG : Methylparaben: magnesium stearate : } \\
\text { Paracetamol / } \\
\text { HPMCAS HG : Methylparaben: magnesium stearate : } \\
\text { Paracetamol / } \\
(75: 15: 5: 5) /(40: 5: 5: 50)\end{array}$ & Printlets & Delayed release & [38] \\
\hline
\end{tabular}


FARMACIA, 2020, Vol. 68, 4

\begin{tabular}{|c|c|c|c|}
\hline Filament composition used (\%) & Dosage form & Drug Release Characteristics & Reference \\
\hline $\begin{array}{c}\text { HPMC (Affinisol }^{\circledR} \text { 15LV) : ERS : Kolliphor }{ }^{\circledR} \text { TPGS : Carvedilol } \\
(60: 15: 5: 20)\end{array}$ & $\begin{array}{c}\text { Floating } \\
\text { Tablet }\end{array}$ & Sustained release & {$[48]$} \\
\hline HPC-SSL: Triacetin : Theophylline (45:5:50) & Gaplet & Immediate release & [6] \\
\hline $\begin{array}{c}\text { HPC-SSL : Kollidon }{ }^{\circledR} \text { SR : Kolliphor TPGS : Carvedilol } \\
(60: 15: 5: 20)\end{array}$ & Tablet & Sustained release & {$[49]$} \\
\hline $\begin{array}{l}\text { PEO } 200 \mathrm{~K} \text { : starch: sodium lauryl sulphate : Ibuprofen } \\
\text { (40:18:2:40) } \\
\text { PVA : Sodium starch glycolate : Acetaminophen }(73: 7: 20)\end{array}$ & $\begin{array}{l}\text { Orally } \\
\text { disintegrating } \\
\text { film }\end{array}$ & Immediate release & {$[19]$} \\
\hline $\begin{array}{l}\text { PEO 100/200/300/600/900 K : Theophylline : PEG } 6000 \\
(35: 30: 35)\end{array}$ & $\begin{array}{l}\text { Radiator-like } \\
\text { solid dosage } \\
\text { form }\end{array}$ & Immediate release & {$[50]$} \\
\hline $\begin{array}{c}\text { EPO : TEC : TCP : Hydrochlorothiazide } \\
(46.75: 3.25: 37.5: 12.5)\end{array}$ & $\begin{array}{c}\text { Channelled } \\
\text { tablet }\end{array}$ & Immediate release & [84] \\
\hline ERL : ERS : TEC : Theophylline (22.5:22.5:5:50) & Caplet & Sustained release & [78] \\
\hline $\begin{array}{c}\left.\text { TPU (Elastollan }{ }^{\circledR}\right): \text { Levofloxacin } \\
(99.75: 0.25) /(99.5: 0.5) /(99: 1) \\
\end{array}$ & $\begin{array}{c}\text { Vaginal } \\
\text { mesh }\end{array}$ & Sustained release & {$[16]$} \\
\hline EVA : Indomethacin (95:5 and 85:15) & $\begin{array}{l}\text { Intrauterine } \\
\text { system / sub- } \\
\text { cutaneous rod }\end{array}$ & Sustained release & [28] \\
\hline
\end{tabular}

PVA - Polyvinyl alcohol, PLA - Polylactic acid, PCL - polycaprolactone, PVP - Polyvinylpyrrolidone, HPC - hydroxypropyl cellulose, HPMC - hydroxypropyl methylcellulose, HPMCAS - hydroxypropyl methylcellulose acetate succinate, EC - ethyl cellulose, EPO - Eudragit ${ }^{\circledR}$ EPO, ERS - Eudragit ${ }^{\circledR}$ RS PO, ERL - Eudragit RL PO, PEO - polyethylene oxide, EVA - Ethylene vinyl acetate, TPU - thermoplastic polyurethane, TEC - Triethyl citrate, PEG - polyethylene glycol, TCP - Tri-calcium phosphate

\section{Pharmaceutical potential}

Dependent on the material and design considerations, a wide variety of drug delivery systems can be produced that differ in form, dose, release pattern and are fit to meet the local or systemic therapeutic needs. Table I illustrates the versatility of the technology in terms of design and release outcomes.

Up to this point, the FDM was equally used for the development of immediate (IR) and modified (MR) release dosage forms. Because of the high density structure, these products show mainly sustained (extended) release (SR) potential, the rapid disintegration needing different design solutions like low infill or channelling. Still, the typical, more viscous SR materials pose processability issues, as such formulation and the contribution of each constituent is to be studied more in detail.

Most commonly, the pure hydrophilic polymeric substrates (PVA [76, 101], Eudragit ${ }^{\circledR}$ EPO [42, 78, 84, 85], HPC $[6,78]$, Kollicoat ${ }^{\circledR}$ IR [52], PVP [75]) exhibit immediate release, while pure or the addition of hydrophobic polymers (EC [104], HPMCAS [38], Eudragit ${ }^{\circledR}$ RS/RL [60, 64, 78], PLA [10, 23]) will retain API more. Exceptions from this rule are possible. PVA, as per the sort used, can provide immediate $[76,101]$ or sustained [36, 39] release products. Savino et al. studied mixtures based on different particle sized PVA batches (in the range of $250-5000 \mu \mathrm{m}$ ) and determined that particle size does not impact dissolution, but rather improves extrusion by assuring a better homogeneity [86]. P LA's disintegration is slow making it a commonly employed material in biomedical applications [68]. PLA gained increased interest in the fabrication of bone scaffolds, the PLA/hydroxyapatite composites constituting a promising strategy in the development of bone mimicking models [21, 102]. HPMC, although hydrophilic, its high viscosity assures a sustained release $[49,105,106]$, still fast release can also be obtained by design modulation [56].

The main advantage of the 3DP methodology is the easy customization of the design [65]. The design can be modulated at different levels. Already at the predefinition special solutions can be added to the CAD design for a specific purpose. This aspect is of interest mostly in implantology, as to fit the physiological requirements of the administration site. However, by modifying the form, inevitably dose and release are also impacted $[5,76,78]$ due to the changes in the surface area against volume ratio [41]. Sadia et al. trying to resolve the shortcomings of 3DP-FDM in assuring immediate release systems developed a channelled tablet design with an optimized Eudragit ${ }^{\circledR}$ EPO:Triethyl citrate:Tri-calcium phosphate:drug combination [85] and studied the influence of channel width and length on release. They concluded that a channel width greater than $0.6 \mathrm{~mm}$ is decisive in achieving fast release that meets the conditions of the United States Pharmacopoeia for IR formulations [84]. Tagami et al. also studied the influence of holes but on suppositories, ultimately using them for drug loading, while forming Matryoshka type dosage forms [92]. Linares et al. also employed 3DP-FDM only to create the scaffold structures. In this case, loading was assured by injection volume filling [67]. Design modulation can also be done at slicing. For release infill, shell, layer height settings are important to be taken into consideration. The increase of release by means of infill reduction $[33,56,64,100]$, shell reduction and layer thickening [48] has been reported in several 
previous publications. The design characteristics can be exploited in other directions also. Low infill can enable floatation, while shell can impact structural integrity [48].

The 3DP-FDM technology is versatile. Different material substrates can be combined within the same formulation. Some printers have more than one extruder, which allows the use of different filaments in different segments of the dosage form. The dosage forms can deliver one specific or multiple APIs, separated by layering [77] or compartmentalization [27], with similar or different dissolution kinetics.

The core-shell compartmentalization can be used as an alternative coating procedure in order to modify the release $[57,66]$ or to protect the API from degradation [59]. Delaying the release [29, 74] or obtaining zero order [45] kinetics is also possible with this design solution.

\section{Applicability}

Three-dimensional printing has a great potential to become the major disruptive technology worldwide. For the pharmaceutical industry, an important promising application is the replacement of conventional mass tablet production towards low scale manufacturing of personalized dosage forms in decentralized facilities such as local hospitals or pharmacies. Among the economical and logistical advantages, the transportation and storage fees could be significantly decreased [54]. Moreover, the proximity to the product receiver allows immediate responses and adjustments to the patients' need.

Precision medicine and personalized therapy are among the major initiatives of the $21^{\text {th }}$ century in medical sciences [32]. Due to the flexibility of the manufacturing process expressed in form, dose and release adaptations, 3DP is able to align to the requirements of personalization, meant to assure efficiency and compliance to the therapeutic approach (Figure 3).

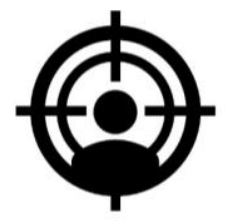

Personalization

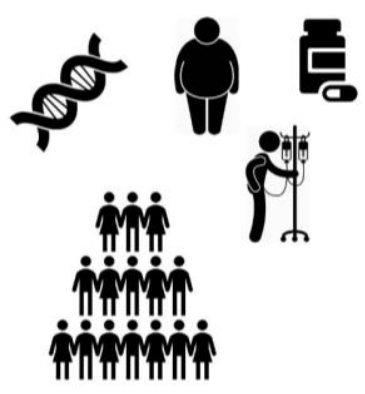

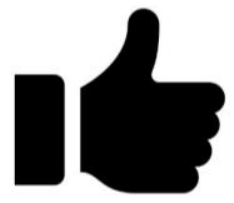

Compliance

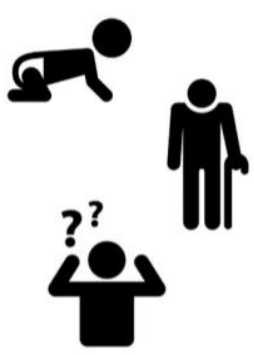

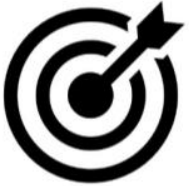

Targeting

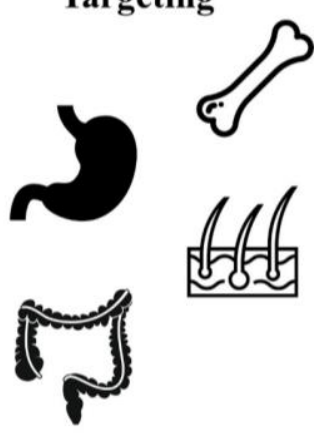

Figure 3.

The therapeutic potentials of 3DP-FDM: personalization based on individual needs, increase in acceptability and compliance for special categories, therapeutic targeting by design adaptation

Paediatric and geriatric populations are the major sectors that would benefit from personalized dosage forms. The flexibility in adjusting the shape and size is set to aid age or pathology related problematic deglutition. Orally disintegrating films (ODF) and minitablets are acknowledged to be innovative solutions in this direction [80]. 3DP-FDM is capable of producing both with the simple modulation in design. Jamróz et al. produced aripiprazol loaded PVA based printed and film casted ODFs and compared their efficiency. The 3DP formulation was shown to provide more reproducible results and a faster release due to the amorphization of the API [51]. Palekar et al., besides producing baclofen minicaplets, also took into account the need of dose and release personalization. Adaptation was done based on a quality by design approach taking into consideration the design features (size, infill) [76]. Tailored dosing is particularly essential for APIs with narrow therapeutic windows, independent of the population for which it is used. The heterogeneity of the population due to genetics, associated pathologies and medications, can cause inter-individual variation in the dose required to achieve therapeutic response. Based on this premises Arafat et al. developed individualized warfarin formulations and tested them on rats [5]. Additionally, dosing by design is set to replace tablet splitting. In this regard, Zheng et al. proved that, compared to the conventional subdivision, a more accurate and safe dosing can be obtained by this new approach, for spironolactone and hydrochlorothiazide tablets [107].

The compliance to the therapy is a key factor in assuring efficiency. For children, shape, as well as colour and 
FARMACIA, 2020, Vol. 68, 4

taste can influence the compliance to therapy. With this scope, Scoutaris et al. developed paediatric Starmix ${ }^{\circledR}$ designs with taste masking being assured by a HPMCAS based formulation [87]. The geriatric population may face another difficulty: the need for polymedication, which occasionally can be accompanied by impaired cognitive functions. Polypills associate multiple active substances within one product and can aid adherence to the treatment by reducing the number of administrations required. The need for polypharmacy is acknowledged $[12,83]$, but the production in the conventional setups causes technological difficulties. Pereira et al., with a simple HME + 3DP-FDM methodology, combined 4 medications for hypertension and dyslipidaemia within one formulation by multi-layering [77].

3DP also introduces the concept of print-on-demand. This approach can be beneficial in case of orphan drug products for rare diseases, meeting population needs without risking fabrication waste [15]. Goyanes et al. conducted the first study in this direction, developing chewable isoleucine formulations for maple syrup urine disease and testing them in clinical settings [40].

Among the available 3DP technologies, 3DP-FDM is certainly the most studied method in pharmaceutical research due to low costs and the accessibility of the printers. Compared to traditional tableting techniques that involve various processing phases, considerable batches and qualified human resources, 3DP-FDM represents a simple and easily adaptable method, manipulable by unsophisticated user interface with minimum operation training necessary [78]. In accordance to its distinctive characteristics and versatility, it appears to be a robust candidate as a platform for personalized dosage form tailoring. Due to the variety of accessible polymers, the release profile of the drug delivery systems, as seen in section 4, is susceptible to modulation from immediate release, to sustained and modified release, without supplementary procedures such as coating [8]. Kinetics can be adapted for every compartment or layer based on API requirements. Another benefit is the possibility of amorphization of the drug during the hot melt extrusion and/or the printing process, which might facilitate the dissolution of the API and ultimately increase bioavailability [49].

Particular geometries can also be enabled by using this technology, which normally are hard to produce. This is the reason why 3DP-FDM was exploited more extensively in the production of implants for which personalization is necessary as to assure acceptability. Drug-eluting pharmaceutical devices can be produced, like dental fillers [103], microneedles [69], wound dressings [37, 71], hernia meshes [81] or gynaecological $[16,26,28,44]$ implants. The design modulation also proved to have an influence on the targeting of different regions of the gastrointestinal tract. Gastro-retentive floating systems can be easily produced by simple infill print settings. Systems can be used as a standalone [14] or constitute an auxiliary floatation device [25]. Ilyés et al. determined that the problems related to the conventional floating systems can be surpassed by 3DP-FDM [48]. Colonic delivery can also be achieved by using appropriate enteric materials [67].

\section{Limitations}

The significant restriction of 3DP-FDM is the limitation of use for thermally stable components, as a result of the elevated temperatures linked with the process [35]. The range of materials that can be applied is however much lower. As per section Material requirements, 3DP-FDM printability is multifactorial requiring specific material characteristics that are hard to obtain with pharmaceutical excipients [49].

Stability studies will be critical like for any other polymeric system. Filament aging could cause unwanted interactions between the constituents of the filament and modifications of the moisture content which may have an impact on the stability of the drug and the characteristics of the printed product [53]. Although amorphous solid dispersions can be formed during processing, recrystallization is a significant risk to be monitored during shelf-life [49].

As per productivity, compared to other 3DP techniques, the production is slower. The integration of 3DP-FDM within the industrial sector is still disputable, reliant of further apparatus improvements as to increase print speed and enable scale-up.

Regardless of the series of advantages, transferring the production of dosage forms to decentralized facilities raises several issues regarding legal, ethical and regulatory concerns. The transport and the storage of the raw material, the development of quality controls and the counterfeit fabrication risk management are just few of the aspects that need to be established [62].

\section{Conclusions}

$3 \mathrm{D}$ printing proves to be a rapidly evolving, groundbreaking technology within the pharmaceutical field, presenting great potential in overcoming the inconveniences of conventional manufacturing techniques. Highly flexible, complex formulations with tailored drug release characteristics can be prepared through a simple technology which is set to be an effective tool towards further development of patient-centred medicine.

3DP-FDM stands out among other available methods through versatility, portability and cost-effectiveness, but several challenges need to be surpassed prior to general integration into pharmaceutical dosage form production, including enhancement of quality and safety features.

As a global perspective, it is expected that the fabrication of high-volume pharmaceutical dosage forms will further be completed by conventional methods in centralized manufacturing units and the 3DP technique 
will be preserved as a complementary tool for personalized medicine in particular cases.

\section{Acknowledgement}

The authors acknowledge the financial support received through the Iuliu Hatieganu internal doctoral research grant 2461/37/17.01.2020 and the Collegium Talentum 2019 Program of Hungary. This paper was published under the frame of European Social Found, Human Capital Operational Program 2014-2020, project no. POCU/380/6/13/125171.

\section{Conflict of interest}

The authors declare no conflict of interest.

\section{References}

1. Aho J, Van Renterghem J, Arnfast L, De Beer T, Rantanen J, The flow properties and presence of crystals in drug-polymer mixtures: Rheological investigation combined with light microscopy. Int J Pharm., 2017; 528(1-2): 383-394.

2. Aho J, B $\varnothing$ tker JP, Genina N, Edinger M, Arnfast L, Rantanen J, Roadmap to 3D-printed oral pharmaceutical dosage forms: feedstock filament properties and characterization for fused deposition modeling. J Pharm Sci., 2019; 108(1): 26-35.

3. Alhijjaj M, Belton P, Qi S, An investigation into the use of polymer blends to improve the printability of and regulate drug release from pharmaceutical solid dispersions prepared via fused deposition modeling (FDM) 3D printing. Eur J Pharm Biopharm., 2016; 108: 111-125.

4. Alhijjaj M, Nasereddin J, Belton P, Qi S, Impact of processing parameters on the quality of pharmaceutical solid dosage forms produced by fused deposition modeling (FDM). Pharmaceutics, 2019; 11(12): 1-21.

5. Arafat B, Qinna N, Cieszynska M, Forbes RT, Alhnan MA, Tailored on demand anti-coagulant dosing: An in vitro and in vivo evaluation of $3 \mathrm{D}$ printed purposedesigned oral dosage forms. Eur J Pharm Biopharm., 2018(128): 282-289;

6. Arafat B, Wojsz M, Isreb A, Forbes RT, Isreb M, Ahmed W, Arafat T, Alhnan MA, Tablet fragmentation without a disintegrant: A novel design approach for accelerating disintegration and drug release from 3D printed cellulosic tablets. Eur J Pharm Sci., 2018; 118: 191-199.

7. Autodesk Design Academy, Introduction to the Fusion 360 API, www.youtube.com.

8. Awad A, Trenfield SJ, Gaisford S, Basit AW. 3D printed medicines: A new branch of digital healthcare. Int J Pharm., 2018; 548(1): 586-596.

9. Azad O, Kimbell B, Hossain S, Polymers for extrusionbased 3D printing of pharmaceuticals: a holistic materialsprocess perspective. Pharmaceutics, 2020; 12(2): 1-34.

10. Boetker J, Water JJ, Aho J, Arnfast L, Bohr A, Modifying release characteristics from $3 \mathrm{D}$ printed drug-eluting products. Eur J Pharm Sci., 2016; 90: 47-52.

11. Calvo NL, Maggio RM, Kaufman TS, Characterization of pharmaceutically relevant materials at the solid state employing chemometrics methods. J Pharm Biomed Anal., 2018; 147: 538-564.

12. Castellano JM, Verdejo J, Ocampo S, Rios MM, Gómez-Álvarez E, Borrayo G, Ruiz E, Ibáñez B, Fuster $\mathrm{V}$, Clinical effectiveness of the cardiovascular polypill in a real-life setting in patients with cardiovascular risk in Mexico: The SORS Study. Arch Med Res., 2019; 50(1): 31-40.

13. Censi R, Gigliobianco MR, Casadidio C, Di Martino $\mathrm{P}$, Hot melt extrusion: highlighting physicochemical factors to be investigated while designing and optimizing a hot melt extrusion process. Pharmaceutics, 2018; 10(3): 1-27.

14. Chai X, Chai H, Wang X, Yang J, Li J, Zhao Y, Cai W, Tao T, Xiang X, Fused deposition modeling (FDM) 3D printed tablets for intragastric floating delivery of domperidone. Sci Rep., 2017; 7(1): 1-9.

15. Chen D, Heyer S, Ibbotson S, Salonitis K, Steingrímsson JG, Thiede S, Direct digital manufacturing: Definition, evolution, and sustainability implications. J Clean Prod., 2015; 107: 615-625.

16. Domínguez-Robles J, Mancinelli C, Mancuso E, GarcíaRomero I, Gilmore BF, Casettari L, Larrañeta E, Lamprou DA, 3D printing of drug-loaded thermoplastic polyurethane meshes: a potential material for soft tissue reinforcement in vaginal surgery. Pharmaceutics, 2020; 12(1): 1-15.

17. Drăgănescu D, Lupuliasa D, Burcea Dragomiroiu GTA, Roșca AC, Hîncu L, Cioacă D, 3D printing pharmaceutical formulation of drugs in personalized therapy. Farmacia, 2019; 67(1): 1-9.

18. Dumitrescu IB, Lupuliasa D, Drăgoi CM, Nicolae AC, Pop A, Șaramet G, Drăgănescu D, The age of pharmaceutical 3D printing. Technological and therapeutical implications of additive manufacturing. Farmacia, 2018; 66(3): 365-389.

19. Ehtezazi T, Algellay M, Islam Y, Roberts M, Dempster NM, Sarker SD, The Application of 3D printing in the formulation of multilayered fast dissolving oral films. J Pharm Sci., 2018; 107(4): 1076-1085.

20. Eleftheriadis GK, Ritzoulis C, Bouropoulos N, Tzetzis D, Andreadis DA, Boetker J, Rantanen J, Fatouros DG, Unidirectional drug release from $3 \mathrm{D}$ printed mucoadhesive buccal films using FDM technology: In vitro and ex vivo evaluation. Eur J Pharm Biopharm., 2019; 144: 180-192.

21. Esposito CC, Gervaso F, Scalera F, Padmanabhan SK, Madaghiele M, Montagna F, Sannino A, Licciulli A, Maffezzoli A, Highly loaded hydroxyapatite microsphere/ PLA porous scaffolds obtained by fused deposition modelling. Ceram Int., 2019; 45(2): 2803-2810.

22. European Medicines Agency, ICH guideline Q3C (R6) on impurities: guideline for residual solvents Step 5, www.ema.europa.eu.

23. Farto-Vaamonde X, Auriemma G, Aquino RP, Concheiro A, Alvarez-Lorenzo C, Post-manufacture loading of filaments and 3D printed PLA scaffolds with prednisolone and dexamethasone for tissue regeneration applications. Eur J Pharm Biopharm., 2019; 141: 100-110.

24. FDA, FDA-Approved Drugs - Spirtam (Aprecia) NDA 207958, www.accessdata.fda.gov.

25. Fu J, Yin H, Yu X, Xie C, Jiang H, Jin Y, Sheng F, Combination of 3D printing technologies and compressed tablets for preparation of riboflavin floating tablet-in- 
device (TiD) systems. Int J Pharm., 2018; 549(1-2): 370-379.

26. $\mathrm{Fu}$ J, $\mathrm{Yu} \mathrm{X}$, Jin $\mathrm{Y}, 3 \mathrm{D}$ printing of vaginal rings with personalized shapes for controlled release of progesterone. Int J Pharm., 2018; 539(1-2): 75-82.

27. Genina N, Boetker JP, Colombo S, Harmankaya N, Rantanen J, Bohr A, Anti-tuberculosis drug combination for controlled oral delivery using $3 \mathrm{D}$ printed compartmental dosage forms: From drug product design to in vivo testing. J Control Release, 2017; 268: 40-48.

28. Genina N, Holländer J, Jukarainen H, Mäkilä E, Salonen J, Sandler N, Ethylene vinyl acetate (EVA) as a new drug carrier for 3D printed medical drug delivery devices. Eur J Pharm Sci., 2015; 90: 53-36.

29. Gioumouxouzis CI, Tzimtzimis E, Katsamenis OL, Dourou A, Markopoulou C, Bouropoulos N, Tzetzis D, Fatouros DG, Fabrication of an osmotic 3D printed solid dosage form for controlled release of active pharmaceutical ingredients. Eur J Pharm Sci., 2020; 143: 105176, doi: https://doi.org/10.1016/j.ejps.2019. 105176.

30. Go J, Schiffres SN, Stevens AG, Hart AJ, Rate limits of additive manufacturing by fused filament fabrication and guidelines for high-throughput system design. Addit Manuf., 2017; 16: 1-11.

31. Goole J, Amighi K, 3D printing in pharmaceutics: A new tool for designing customized drug delivery systems. Int J Pharm., 2016; 499(1): 376-394.

32. Govender R, Abrahmsén-Alami S, Larsson A, Folestad $\mathrm{S}$, Therapy for the individual: Towards patient integration into the manufacturing and provision of pharmaceuticals. Eur J Pharm Biopharm., 2020; 149: 58-76.

33. Goyanes A, Buanz ABM, Basit AW, Gaisford S, Fused-filament 3D printing (3DP) for fabrication of tablets. Int J Pharm., 2014; 476(1): 88-92.

34. Goyanes A, Buanz ABM, Hatton GB, Gaisford S, Basit AW, 3D printing of modified-release aminosalicylate (4-ASA and 5-ASA) tablets. Eur J Pharm Biopharm., 2015; 89:157-162.

35. Goyanes A, Buanz ABM, Hatton GB, Gaisford S, Basit AW, 3D printing of modified-release aminosalicylate (4-ASA and 5-ASA) tablets. Eur J Pharm Biopharm., 2015; 89: 157-162.

36. Goyanes A, Buanz ABM, Basit AW, Gaisford S, Fused-filament 3D printing (3DP) for fabrication of tablets. Int J Pharm., 2014; 476(1-2): 88-92.

37. Goyanes A, Det-Amornrat U, Wang J, Basit AW, Gaisford S, 3D scanning and 3D printing as innovative technologies for fabricating personalized topical drug delivery systems. J Control Release, 2016; 234: 41-48.

38. Goyanes A, Fina F, Martorana A, Sedough D, Gaisford $\mathrm{S}$, Basit AW, Development of modified release 3D printed tablets (printlets) with pharmaceutical excipients using additive manufacturing. Int J Pharm., 2017; 527(1-2): 21-30.

39. Goyanes A, Kobayashi M, Martínez-Pacheco R, Gaisford S, Basit AW, Fused-filament 3D printing of drug products: Microstructure analysis and drug release characteristics of PVA-based caplets. Int J Pharm., 2016; 514(1): 290-295.

40. Goyanes A, Madla CM, Umerji A, Duran Piñeiro G, Giraldez Montero JM, Lamas Diaz MJ, Gonzalez Barcia M, Taherali F, Sánchez-Pintos P, Couce ML, Gaisford S, Basit AW, Automated therapy preparation of isoleucine formulations using $3 \mathrm{D}$ printing for the treatment of MSUD: First single-centre, prospective, crossover study in patients. Int J Pharm., 2019; 567: 1-8.

41. Goyanes A, Robles Martinez P, Basit AW, Effect of geometry on drug release from 3D printed tablets. Int J Pharm., 2015; 494(2): 657-663.

42. Gültekin HE, Tort S, Acartürk F, An effective technology for the development of immediate release solid dosage forms containing low-dose drug: fused deposition modeling 3D Printing. Pharm Res., 2019; 36(9): 1-13.

43. Gupta SS, Solanki N, Serajuddin ATM, Investigation of Thermal and Viscoelastic Properties of Polymers Relevant to Hot Melt Extrusion, IV: Affinisol ${ }^{\mathrm{TM}}$ HPMC HME Polymers. AAPS PharmSciTech., 2016; 17(1): 148-157.

44. Holländer J, Genina N, Jukarainen H, Khajeheian M, Rosling A, Mäkilä E, Sandler N, Three-dimensional printed PCL-Based implantable prototypes of medical devices for controlled drug delivery. J Pharm Sci., 2016; 105(9): 2665-2676.

45. Huanbutta K, Sangnim T, Design and development of zero-order drug release gastroretentive floating tablets fabricated by 3D printing technology. J Drug Deliv Sci Technol., 2019; 52: 831-837.

46. Huang S, O'Donnell KP, Keen JM, Rickard MA, McGinity JW, Williams RO, A New Extrudable Form of Hypromellose: AFFINISOL ${ }^{\mathrm{TM}}$ HPMC HME. AAPS PharmSciTech., 2016; 17(1): 106-119.

47. Ibrahim M, Barnes M, McMillin R, Cook DW, Smith S, Halquist M, Wijesinghe D, Roper TD, 3D Printing of Metformin HCl PVA Tablets by Fused Deposition Modeling: Drug Loading, Tablet Design, and Dissolution Studies. AAPS PharmSciTech., 2019; 20(5): 1-11.

48. Ilyés K, Balogh A, Casian T, Igricz T, Borbás E, Démuth B, Vass P, Menyhárt L, Kovács NK, Marosi G, Tomuță I, Nagy ZK, 3D floating tablets: Appropriate $3 \mathrm{D}$ design from the perspective of different in vitro dissolution testing methodologies. Int J Pharm., 2019; 567: 1-11.

49. Ilyés K, Kovács NK, Balogh A, Borbás E, Farkas B, Casian T, Marosi G, Tomuță I, Nagy ZK, The applicability of pharmaceutical polymeric blends for the fused deposition modelling (FDM) 3D technique: Material considerations-printability-process modulation, with consecutive effects on in vitro release, stability and degradation. Eur J Pharm Sci., 2019; 129: 110-123.

50. Isreb A, Baj K, Wojsz M, Isreb M, Peak M, Alhnan MA, 3D printed oral theophylline doses with innovative "radiator-like" design: Impact of polyethylene oxide (PEO) molecular weight. Int J Pharm., 2019; 564: 98-105.

51. Jamroz W, Kurek M, Lyszczarz E, Szafraniec J, Knapik-Kowalczuk J, Syrek K, Paluch M, Jachowicz R, 3D printed orodispersible films with Aripiprazole. Int J Pharm., 2017; 533(2): 413-420.

52. Jamróz W, Kurek M, Szafraniec-Szczęsny J, Czech A, Gawlak K, Knapik-Kowalczuk J, Leszczyński B, Wróbel A, Paluch M, Jachowicz R, Speed it up, slow it down...An issue of bicalutamide release from 3D printed tablets. Eur J Pharm Sci., 2020; 143: 105169, https://doi.org/10.1016/j.ejps.2019.105169.

53. Jamróz W, Szafraniec J, Kurek M, Jachowicz R, 3D Printing in pharmaceutical and medical applications - 
Recent achievements and challenges. Pharm Res., 2018; 35(9): 1-22.

54. Janssen R, Blankers I, Moolenburgh E, Posthumus Date B, TNO: The impact of 3-D printing on supply chain management, http://3din.nl.

55. Jones DS, Tian Y, Abu-Diak O, Andrews GP, Pharmaceutical applications of dynamic mechanical thermal analysis. Adv Drug Delivery Rev., 2012; 64(2): 440-448.

56. Kadry H, Al-Hilal TA, Keshavarz A, Alam F, Xu C, Joy A, Ahsan F, Multi-purposable filaments of HPMC for 3D printing of medications with tailored drug release and timed-absorption. Int J Pharm., 2018; 544: 285-296.

57. Kadry H, Al-Hilal TA, Keshavarz A, Alam F, Xu C, Joy A, Ahsan F, Multi-purposable filaments of HPMC for 3D printing of medications with tailored drug release and timed-absorption. Int J Pharm., 2018; 544: 285-296.

58. Kallakunta VR, Sarabu S, Bandari S, Tiwari R, Patil H, Repka MA, An update on the contribution of hotmelt extrusion technology to novel drug delivery in the twenty-first century: part I. Expert Opin Drug Deliv., 2019; 16: 539-550.

59. Kempin W, Domsta V, Brecht I, Semmling B, Tillmann S, Weitschies W, Seidlitz A, Development of a dual extrusion printing technique for an acid- and thermolabile drug. Eur J Pharm Sci., 2018; 123: 191-198.

60. Kempin W, Franz C, Koster LC, Schneider F, Bogdahn M, Weitschies W, Seidlitz A, Assessment of different polymers and drug loads for fused deposition modeling of drug loaded implants. Eur J Pharm Biopharm., 2017; 115: 84-93.

61. Khatri P, Desai D, Shelke N, Minko T, Role of plasticizer in membrane coated extended release oral drug delivery system. J Drug Delivery Sci Technol., 2018; 44: 231-243.

62. Kietzmann J, Pitt L, Berthon P, Disruptions, decisions, and destinations: Enter the age of 3-D printing and additive manufacturing. Bus Horiz., 2015; 58(2): 209-215.

63. Kollamaram G, Croker DM, Walker GM, Goyanes A, Basit AW, Gaisford S, Low temperature fused deposition modeling (FDM) 3D printing of thermolabile drugs. Int J Pharm., 2018; 545(1-2): 144-152.

64. Korte C, Quodbach J, 3D-Printed Network Structures as Controlled-Release Drug Delivery Systems: Dose Adjustment, API Release Analysis and Prediction. AAPS PharmSciTech., 2018; 19(8): 3333-3342.

65. Lamichhane S, Bashyal S, Keum T, Noh G, Seo JE, Bastola R, Choi J, Sohn DH, Lee S, Complex formulations, simple techniques: Can 3D printing technology be the Midas touch in pharmaceutical industry?. Asian J Pharm Sci., 2019; 14(5): 465-479.

66. Li Q, Wen H, Jia D, Guan X, Pan H, Yang Y, Yu S, Zhu Z, Xiang R, Pan W, Preparation and investigation of controlled-release glipizide novel oral device with three-dimensional printing. Int J Pharm., 2017; 525(1): 5-11.

67. Linares V, Casas M, Caraballo I, Printfills: 3D printed systems combining fused deposition modeling and injection volume filling. Application to colon-specific drug delivery. Eur J Pharm Biopharm., 2019; 134: 138-143.
68. Lupuleasa D, Drăgănescu D, Hîncu L, Tudosă CP, Cioacă D, Biocompatible polymers for $3 \mathrm{D}$ printing. Farmacia, 2018; 66(5): 737-746.

69. Luzuriaga MA, Berry DR, Reagan JC, Smaldone RA, Gassensmith JJ, Biodegradable 3D printed polymer microneedles for transdermal drug delivery. Lab Chip., 2018; 18(8): 1223-1230.

70. Melocchi A, Parietti F, Maroni A, Foppoli A, Gazzaniga A, Zema L, Hot-melt extruded filaments based on pharmaceutical grade polymers for 3D printing by fused deposition modeling. Int J Pharm., 2016; 509(1): 255-263.

71. Muwaffak Z, Goyanes A, Clark V, Basit AW, Hilton ST, Gaisford S, Patient-specific 3D scanned and 3D printed antimicrobial polycaprolactone wound dressings. Int J Pharm., 2017; 527(1-2): 161-170.

72. Nasereddin JM, Wellner N, Alhijjaj M, Belton P, Qi S, Development of a simple mechanical screening method for predicting the feedability of a pharmaceutical FDM 3D printing filament. Pharm Res., 2018; 35(8): $1-13$.

73. Ngo TD, Kashani A, Imbalzano G, Nguyen KTQ, Hui D, Additive manufacturing (3D printing): A review of materials, methods, applications and challenges. Compos B Eng., 2018; 143: 172-196.

74. Okwuosa TC, Pereira BC, Arafat B, Cieszynska M, Isreb A, Alhnan MA, Fabricating a shell-core delayed release tablet using dual FDM 3D printing for patientcentred therapy. Pharm Res., 2017; 34(2): 427-437.

75. Okwuosa TC, Stefaniak D, Arafat B, Isreb A, Wan K-W, Alhnan MA, A lower temperature FDM 3D printing for the manufacture of patient-specific immediate release tablets. Pharm Res., 2016; 33(11): 2704-2712.

76. Palekar S, Nukala PK, Mishra SM, Kipping T, Patel K, Application of 3D printing technology and quality by design approach for development of age-appropriate pediatric formulation of baclofen. Int J Pharm., 2019; 556: 106-116.

77. Pereira BC, Isreb A, Forbes RT, Dores F, Habashy R, Petit JB, Alhnan MA, Oga EF, 'Temporary Plasticiser': A novel solution to fabricate 3D printed patientcentred cardiovascular 'Polypill' architectures. Eur J Pharm Biopharm., 2019; 135: 94-103.

78. Pietrzak K, Isreb A, Alhnan MA, A flexible-dose dispenser for immediate and extended release 3D printed tablets. Eur J Pharm Biopharm., 2015; 96: 380-387.

79. Prasad E, Islam MT, Goodwin DJ, Megarry AJ, Halbert GW, Florence AJ, Robertson J, Development of a hotmelt extrusion (HME) process to produce drug loaded Affinisol $^{\mathrm{TM}} 15 \mathrm{LV}$ filaments for fused filament fabrication (FFF) 3D printing. Addit Manuf., 2019; 29: 1-16.

80. Preis M, Orally disintegrating films and mini-tabletsInnovative dosage forms of choice for pediatric use. AAPS PharmSciTech., 2015; 16(2): 234-241.

81. Qamar N, Abbas N, Irfan M, Hussain A, Arshad MS, Latif S, Mehmood F, Ghori MU, Personalized 3D printed ciprofloxacin impregnated meshes for the management of hernia. J Drug Deliv Sci Technol., 2019; 53: 1-8.

82. Repka MA, Langley N, DiNunzio J, Melt Extrusion. Materials, Technology and Drug Product Design, Springer, 2013. 
83. Rosenthal T, Can a polypill one single tablet combat different cardiovascular risk factors? J Am Soc Hypertens., 2018; 12(5): 335-339.

84. Sadia M, Arafat B, Ahmed W, Forbes RT, Alhnan MA, Channelled tablets: An innovative approach to accelerating drug release from $3 \mathrm{D}$ printed tablets. $J$ Control Release, 2018; 269: 355-363.

85. Sadia M, So Snicka A, Arafat B, Isreb A, Ahmed W, Kelarakis A, Alhnan MA, Adaptation of pharmaceutical excipients to FDM 3D printing for the fabrication of patient-tailored immediate release tablets. Int J Pharm., 2016; 513(1-2): 659-668.

86. Saviano M, Aquino RP, Del Gaudio P, Sansone F, Russo P, Poly(vinyl alcohol) 3D printed tablets: The effect of polymer particle size on drug loading and process efficiency. Int J Pharm., 2019; 561: 1-8.

87. Scoutaris N, Ross SA, Douroumis D, 3D printed "Starmix" drug loaded dosage forms for paediatric applications. Pharm Res., 2018; 35(2): 1-11.

88. Skowyra J, Pietrzak K, Alhnan MA, Fabrication of extended-release patient-tailored prednisolone tablets via fused deposition modelling (FDM) 3D printing. Eur J Pharm Sci., 2015; 68: 11-17.

89. Solanki NG, Tahsin M, Shah AV, Serajuddin ATM, Formulation of 3D Printed Tablet for Rapid Drug Release by Fused Deposition Modeling: Screening Polymers for Drug Release, Drug-Polymer Miscibility and Printability. J Pharm Sci., 2018; 107(1): 390-401.

90. Suwardie H, Wang P, Todd DB, Panchal V, Yang M, Gogos CG, Rheological study of the mixture of acetaminophen and polyethylene oxide for hot-melt extrusion application. Eur J Pharm Biopharm., 2011; 78(3): 506-512.

91. Tagami T, Fukushige K, Ogawa E, Hayashi N, Ozeki T, 3D Printing factors important for the fabrication of polyvinylalcohol filament-based tablets. Biol Pharm Bull., 2017; 40(3): 357-364.

92. Tagami T, Hayashi N, Sakai N, Ozeki T, 3D printing of unique water-soluble polymer-based suppository shell for controlled drug release. Int J Pharm., 2019; 568: 1-8.

93. Tagami T, Kuwata E, Sakai N, Ozeki T, Drug incorporation into polymer filament using simple soaking method for tablet preparation using fused deposition modeling. Biol Pharm Bull., 2019; 42(10): 1753-1760.

94. Tanikella NG, Wittbrodt B, Pearce JM, Tensile strength of commercial polymer materials for fused filament fabrication 3D printing. Addit Manuf., 2017; 15: 40-47.

95. Tappa K, Jammalamadaka U, Ballard DH, Bruno T, Israel MR, Vemula H, Meacham JM, Mills DK, Woodard PK, Weisman JA, Medication eluting devices for the field of OBGYN (MEDOBGYN): 3D printed biodegradable hormone eluting constructs, a proof of concept study. PLoS One, 2017; 12(8): 1-17.
96. Thakkar R, Thakkar R, Pillai A, Ashour EA, Repka MA, Systematic screening of pharmaceutical polymers for hot melt extrusion processing: a comprehensive review. Int J Pharm., 2020; 576: 1-18.

97. Thiry J, Krier F, Evrard B, A review of pharmaceutical extrusion: Critical process parameters and scalingup. Int J Pharm., 2015; 479(1): 227-240.

98. Tidau M, Kwade A, Finke JH, Influence of high, disperse api load on properties along the fusedlayer modeling process chain of solid dosage forms. Pharmaceutics, 2019; 11(4): 1-17.

99. Trivedi M, Jee J, Silva S, Blomgren C, Pontinha VM, Dixon DL, Additive manufacturing of pharmaceuticals for precision medicine applications: A review of the promises and perils in implementation. Addit Manuf., 2018; 23: 319-328.

100. Verstraete G, Samaro A, Grymonpré W, Vanhoorne V, Snick B Van, Boone MN, Hellemans T, Van Hoorebeke L, Remon JP, Vervaet C, 3D printing of high drug loaded dosage forms using thermoplastic polyurethanes. Int J Pharm., 2018; 536: 318-325.

101. Wei C, Solanki NG, Vasoya JM, Shah AV, Serajuddin ATM, Development of 3D printed tablets by fused deposition modeling using polyvinyl alcohol as polymeric matrix for rapid drug release. J Pharm Sci., 2020; 109(4): 1558-1572.

102. Wu D, Spanou A, Diez-Escudero A, Persson C, 3Dprinted PLA/HA composite structures as synthetic trabecular bone: A feasibility study using fused deposition modeling. J Mech Behav Biomed Mater., 2020; 103: 1-10.

103. Yang Y, Li H, Xu Y, Dong Y, Shan W, Shen J, Fabrication and evaluation of dental fillers using customized molds via 3D printing technology. Int $J$ Pharm., 2019; 562: 66-75.

104. Yang Y, Wang H, Li H, Ou Z, Yang G, 3D printed tablets with internal scaffold structure using ethyl cellulose to achieve sustained ibuprofen release. Eur J Pharm Sci., 2018; 115: 11-18.

105. Zhang J, Feng X, Patil H, Tiwari R V, Repka MA, Coupling 3D printing with hot-melt extrusion to produce controlled-release tablets. Int J Pharm., 2017; 519: 186-197.

106. Zhang J, Yang W, Vo AQ, Feng X, Ye X, Kim DW, Repka MA, Hydroxypropyl methylcellulose-based controlled release dosage by melt extrusion and 3D printing: Structure and drug release correlation. Carbohydr Polym., 2017; 177: 49-57.

107. Zheng Z, Lv J, Yang W, Pi X, Lin W, Lin Z, Zhang W, Pang J, Zeng Y, Lv Z, Lao H, Chen Y, Yang F, Preparation and application of subdivided tablets using 3D printing for precise hospital dispensing. Eur J Pharm Sci., 2020; 149: 1-11. 